\title{
The Septohippocampal System Participates in General Anesthesia
}

\author{
Jingyi Ma, ${ }^{1,2}$ Bixia Shen, ${ }^{1,2}$ Lee S. Stewart, ${ }^{1,4}$ lan A. Herrick, ${ }^{3}$ and L. Stan Leung ${ }^{1,2,4}$ \\ Departments of ${ }^{1}$ Physiology, ${ }^{2}$ Clinical Neurological Sciences, and ${ }^{3}$ Anaesthesiology, and ${ }^{4}$ Program in Neuroscience, \\ University of Western Ontario, London, Ontario, Canada N6A 5A5
}

\begin{abstract}
How the brain mediates general anesthesia is not known. We report that two interconnected structures in the forebrain, the medial septum and the hippocampus, participate in maintaining awareness and movements during general anesthesia. In the awake, freely behaving rat, inactivation of the medial septum or the hippocampus by local injection of a $\mathrm{GABA}_{\mathrm{A}}$ receptor agonist, muscimol, decreased the dose of a general anesthetic needed to induce a loss of the tail-pinch response or a loss of righting reflex. Septohippocampal inactivation also suppressed the behavioral hyperactivity or the delirium stage associated with general anesthesia. An increase and decrease of $30-50 \mathrm{~Hz}$ (gamma) waves in the hippocampus correlated with an increase
\end{abstract}

and decrease in behavioral activity, respectively. Similar results were found for both volatile (halothane and isoflurane) and nonvolatile (propofol and pentobarbital) anesthetics. We conclude that the behavioral hyperactivity induced by a general anesthetic is mediated in part by the septohippocampal system, and that depression of the septohippocampal system increases the potency of a general anesthetic. It is suggested that more potent general anesthetics or adjuvants may be developed by maximizing the pharmacological depression of the septohippocampal system.

Key words: delirium; general anesthetic; gamma rhythm; medial septum; hippocampus; propofol; pentobarbital
A general anesthetic appears to act on lipids and proteins on the membrane and alter synaptic transmission and intrinsic membrane currents in neurons (Krnjevic, 1991; Tanelian et al., 1993; Franks and Lieb, 1994). However, after $>150$ years of clinical use, how general anesthetics act on the brain to mediate general anesthesia is still unclear. In preference to the early theory of depression of the brain-stem reticular formation (Moruzzi and Magoun, 1949; Clark and Rosner, 1973), it is believed that general anesthetics act on different levels of the brain (Stockard and Bickford, 1975; Krnjevic, 1991). So far, the data appear to provide more support for a spinal than a central control of anesthesia (Antognini and Schwartz, 1993; Rampil et al., 1993; Rampil, 1994). Definitive evidence of the involvement of a selective part of the forebrain in general anesthesia has been lacking.

One of the earliest demonstrations of a general anesthetic (in 1844) showed that nitrous oxide induced behavioral excitation or delirium, termed stage II anesthesia (Guedel, 1951). Based on our preliminary data (L. S. Leung, unpublished observations) and the recent literature indicating that the septohippocampal system may induce behavioral hyperactivity (Ma et al., 1996; Oddie et al., 1996; Ma and Leung, 1999; 2000), we initially hypothesized that the medial septum and the hippocampus mediate the delirium stage of general anesthesia. The initial experiments led to a second hypothesis that the inactivation of the septohippocampal system enhances the effects of a general anesthetic.

\footnotetext{
Received Aug. 10, 2001; revised Oct. 29, 2001; accepted Nov. 2, 2001.

This research was supported by the Natural Sciences and Engineering Research Council, by Canadian Institutes of Health Research Grant MT-15685, and by an Ontario Mental Health Foundation postdoctoral fellowship (J.M.). We thank B. MacIver, B. Bland, and C. Vanderwolf for comments on this manuscript.

Correspondence should be addressed to Dr. L. Stan Leung, Department of Clinical Neurological Sciences, University Hospital, University of Western Ontario, London, Ontario, Canada N6A 5A5. E-mail: sleung@uwo.ca.

Copyright (C) 2002 Society for Neuroscience $0270-6474 / 02 / 220001-\bullet \$ 15.00 / 0$
}

\section{MATERIALS AND METHODS}

In male Long-Evans rats under pentobarbital anesthesia, four 23 gauge stainless-steel guide cannulas were implanted above the hippocampus (two per side) according to the following coordinates: posterior (P) 4, lateral $(\mathrm{L}) \pm 2 ; \mathrm{P} 5, \mathrm{~L} \pm 2.5$; relative to bregma (Paxinos and Watson, 1986). A single cannula was implanted above the medial septum [anterior (A) 0.7 , L 0]. After at least $7 \mathrm{~d}$ of recovery, a rat was habituated in a $30 \times$ $30 \times 30 \mathrm{~cm}$ clear Plexiglas chamber. Saline or the $\mathrm{GABA}_{\mathrm{A}}$ receptor agonist muscimol was injected through a 30 gauge inner cannula into the hippocampal CA1 stratum radiatum $(0.5 \mu \mathrm{g}$ of muscimol in $1 \mu \mathrm{l}$ of saline at each site; $1 \mu \mathrm{g}$ of muscimol is equivalent to $8.76 \mathrm{nmol}$ of muscimol) or the medial septum $(1 \mu \mathrm{g}$ of muscimol in $0.6 \mu \mathrm{l}$ of saline unless otherwise noted). Each rat served as its own control in an order-randomized, counter-balanced design, with experiments separated by at least $1 \mathrm{~d}$. A general anesthetic was given 15-20 min after the last injection into the hippocampus and $15 \mathrm{~min}$ after a septal injection. Population spike recordings and dye diffusion indicated that each muscimol injection affected a volume of $\sim 1 \mathrm{~mm}$ radius in $<30 \mathrm{~min}$. Therefore, it is estimated that the two-site muscimol injections into the hippocampus affect $\sim 60 \%$ of each hippocampus, primarily sparing the ventral hippocampus. A single-site injection of muscimol into the hippocampus of each side gave partial results compared with the two-site injections (data not shown). Some rats had an intravenous catheter inserted into the femoral vein under pentobarbital anesthesia at least $2 \mathrm{~d}$ before a propofol experiment. The concentration of halothane and isoflurane (typically 1-3\%) in pure oxygen was determined by specific vaporizers, delivered by a tube into the observation chamber at a flow rate of $81 / \mathrm{min}$, and allowed to leak out from small holes at the top of the chamber. Propofol $(2.5-10 \mathrm{mg} / \mathrm{kg}$, i.v.)

This article is published in The Journal of Neuroscience, Rapid Communications Section, which publishes brief, peerreviewed papers online, not in print. Rapid Communications are posted online approximately one month earlier than they would appear if printed. They are listed in the Table of Contents of the next open issue of JNeurosci. Cite this article as: JNeurosci, 2002, 22:RC200 (1-6). The publication date is the date of posting online at www.jneurosci.org.

http://www.jneurosci.org/cgi/content/full/6006 


\section{Inactivation of the hippocampus}

Figure 1. Inactivation of the hippocampus by muscimol abolished behavioral excitation and enhanced the deep anesthesia induced by a general anesthetic. Rats were injected, in an order-randomized design, with saline or muscimol bilaterally into the hippocampus, and horizontal movements were quantified by the number of infrared beam interruptions in an observation chamber. $A$, Mean and SEM of beam interruptions before hippocampal injection and halothane (same 7 rats per group) do not show a difference between control and muscimol-injected groups. At time 0 , $2 \%$ halothane was introduced into the chamber. Control rats showed an increase in the number of infrared beam interruptions; this increase was significantly larger than that seen in muscimol-injected rats, and was also confirmed by videotape analysis. The anesthetic halothane was replaced by $2 \%$ isoflurane $(B)(n=7)$ and $5 \mathrm{mg} / \mathrm{kg}$ intravenous propofol $(C)(n=7)$. $D-F$, Duration of loss of the tailpinch response or righting reflex (mean plus 1 SEM) was prolonged by muscimol (mus) compared with control saline $(\mathrm{sal})$ injection $(n=7)$. Tests were done in room air after 10 min in halothane $(D)$ and isoflurane $(E)$. F, Pain and righting responses were tested starting $1 \mathrm{~min}$ after administration of $5 \mathrm{mg} / \mathrm{kg}$ intravenous propofol. The absence of a bar for the saline group indicates no mean and SEM or no loss of the tail pinch or righting responses; muscimol- and saline-injected groups were compared in $A-C$ using post hoc $t$ tests after repeated-measures ANOVAs; groups were compared in $D$ and $E$ using paired $t$ tests and compared in $F$ using a paired Wilcoxon test. * $p<0.05$; ${ }^{*} p<0.01 ; * * p<0.005$.

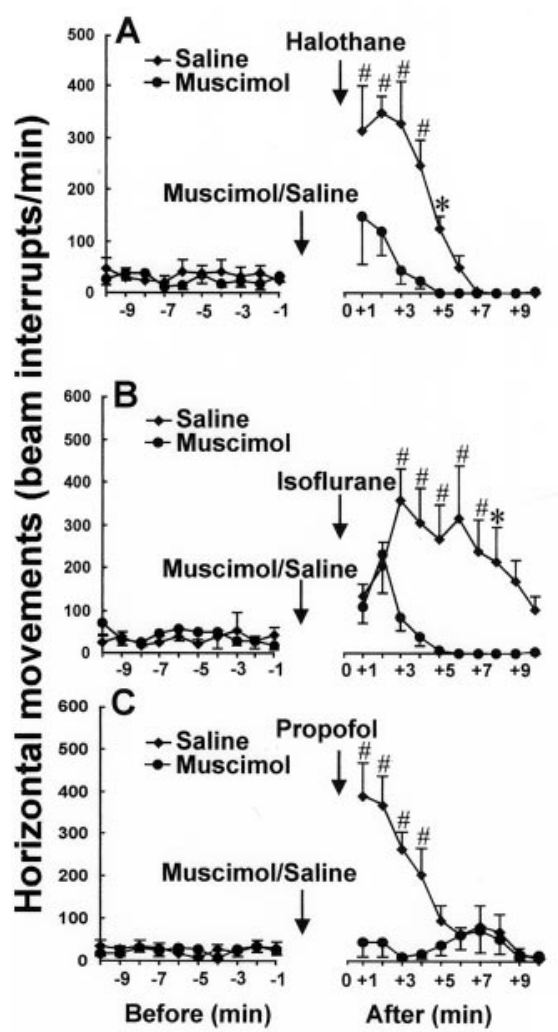

was injected into the femoral vein over $30 \mathrm{sec}$, and pentobarbital (10-60 $\mathrm{mg} / \mathrm{kg}$ ) was injected intraperitoneally. All rats retained spontaneous respiration without apnea for the primary doses of general anesthetics used.

A positive tail-pinch response was considered to be a movement of the body or more than one limb in response to a pinch of the tail by forceps or an alligator clip. The pinch was applied periodically to the middle part of the tail but not to the same part successively. A transient pinch induced a normal rat to move but caused no permanent tissue damage. The righting reflex was considered normal when the rat could right itself from a prone position. Tail-pinch and righting responses were tested in room air $10 \mathrm{~min}$ after exposure to a gaseous anesthetic, $5 \mathrm{~min}$ after pentobarbital injection, or 1 min after propofol injection. Horizontal and vertical movements were quantified by the number of infrared beam interruptions in an observation chamber. Power-spectral analysis of the EEG was done as described previously (Leung, 1985).

\section{RESULTS}

In the first set of experiments, rats were given muscimol or saline control injections bilaterally into the hippocampus through implanted cannulas, 15-20 min before a general anesthetic. Within $30 \mathrm{sec}$ after introduction of $2 \%$ halothane, control rats sniffed, made head movements, and walked around the observation chamber. By $2 \mathrm{~min}$, halothane clearly affected the posture of the control rats, which sometimes showed sudden but small body drops during standing. However, the rats continued to move vigorously, although their limbs were increasingly ataxic. Muscimol-injected rats showed significantly fewer movements than control rats after halothane, as quantified by the interruptions of infrared light beams (Fig. $1 A$ ). Cessation of voluntary movements occurred at 5-6 min after halothane in control rats, significantly longer than the $2-3 \mathrm{~min}$ in muscimol-injected rats $(p<0.01$; Wilcoxon test). Injection of muscimol in the hippocampus did not induce an apparent change in spontaneous behavior or behavioral reactivity. Injection of muscimol in the parietal cortex (1.5 $\mathrm{mm}$ above the hippocampal alvear surface) had no effect on any behavior induced by the anesthetic.

Isoflurane $(2 \%)$ produced similar effects compared with halothane, except it did not abolish movements in some control rats. In contrast, all muscimol-injected rats lost the righting reflex and their ability to move voluntarily after isoflurane. Isofluraneinduced movements were significantly fewer in muscimol- compared with saline-injected rats (Fig. 1B). Control rats given a subanesthetic dose of propofol $(5 \mathrm{mg} / \mathrm{kg}$, i.v.) showed an increase in ataxic walking and circling as well (Fig. $1 C$ ), and all control rats retained their righting reflex. In contrast, muscimol-injected rats showed little behavioral hyperactivity after propofol (Fig. 1C), and five of seven rats lost their ability to move voluntarily $1 \mathrm{~min}$ after administration of $5 \mathrm{mg} / \mathrm{kg}$ intravenous propofol.

At 10 min after the administration of halothane or isoflurane, rats were removed from the chamber and periodically tested for pain responses to tail pinch. Rats with muscimol injected into the hippocampus showed a prolonged suppression of their response to tail pinch compared with control rats (Fig. $1 D, E$ ). In addition, muscimol-injected rats took longer than saline-injected rats to right themselves. After $5 \mathrm{mg} / \mathrm{kg}$ intravenous propofol, only muscimol-injected rats but not saline-injected rats lost their pain and righting responses (Fig. $1 F$ ).

The medial septum controls the electrical activity and functions of the hippocampus through cholinergic and GABAergic pathways (Stumpf, 1965; Bland, 1986; Vanderwolf, 1988; Freund and Buzsaki, 1996). After inactivation of the medial septum by muscimol, a rat was capable of moving but would remain spontaneously immobile if not disturbed (Ma and Leung, 1999, 2000). 


\section{Inactivation of the medial septum}

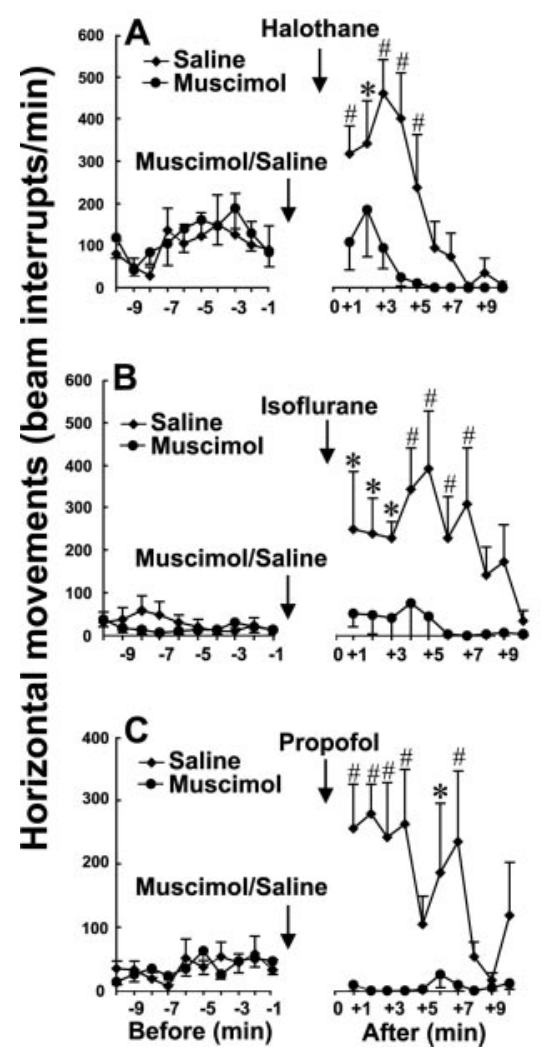

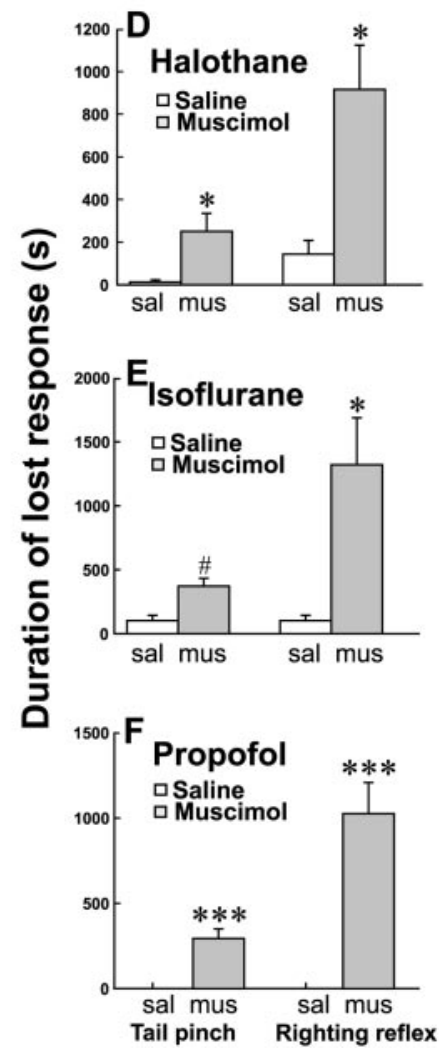

Figure 2. Inactivation of the medial septum by muscimol abolished behavioral excitation and enhanced the deep anesthesia induced by a general anesthetic. Layout and symbols are the same as in Figure 1. The number of infrared beam interruptions is shown before and after $2 \%$ halothane (A) $(n=6), 2 \%$ isoflurane $(B)(n=6)$, and $5 \mathrm{mg} / \mathrm{kg}$ intravenous propofol $(C)(n=8)$. Durations of loss of tail-pinch and righting reflex are shown after $2 \%$ halothane (D) $(n=6), 2 \%$ isoflurane $(E)(n=6)$, and $5 \mathrm{mg} / \mathrm{kg}$ intravenous propofol $(F)(n=8)$. ${ }^{*} p<0.05 ;{ }^{\#} p<0.01$;
The movements induced by halothane, isoflurane, or propofol were significantly suppressed in septum-inactivated rats compared with control rats (Fig. $2 A-C$ ). Also, compared with control rats, septum-inactivated rats showed a prolonged loss of tail-pinch and righting responses after administration of halothane or isoflurane (Fig. 2D,E). Propofol (5 mg/kg, i.v.) abolished righting and tail-pinch responses in septum-inactivated rats but not in control rats (Fig. $2 F$ ). Propofol administered intravenously at 2.5 $\mathrm{mg} / \mathrm{kg}$ or at a lower dose did not abolish righting or pain responses in either septum-inactivated or control rats. When administered intravenously at $10 \mathrm{mg} / \mathrm{kg}$, propofol suppressed righting and tail-pinch responses longer in septum-inactivated rats compared with control rats.

Sodium pentobarbital was injected intraperitoneally in six rats in order-randomized experiments after either muscimol $(0.4 \mu \mathrm{g})$ or control saline injection in the medial septum. Pentobarbital (20 $\mathrm{mg} / \mathrm{kg}$, i.p.) induced behavioral hyperactivity for a few minutes in control rats; the rats then became sedated, but with preserved responses to tail pinch and righting. In contrast, in rats in which muscimol was injected into the medial septum, pentobarbital only induced a brief period of behavioral activity; in addition, the amount of movements was significantly smaller than that seen in control rats (Fig. 3A). Pentobarbital (20 mg/kg, i.p.) abolished the pain and righting responses in five of six rats in which muscimol was injected in the medial septum, but in none of the control rats. As a group, the duration of loss of the tail pinch or the righting response was significantly greater in septum-muscimol-injected rats compared with saline-injected rats (Fig. $3 B$ ). After injection of muscimol $(0.4 \mu \mathrm{g})$ at $2 \mathrm{~mm}$ above the medial septum, approximately in the genu of the corpus callosum, pentobarbital (20 $\mathrm{mg} / \mathrm{kg}$, i.p.) did not induce a loss of pain or righting responses in any rat (Fig. $3 B$ ). In addition, the movements induced by pentobarbital in the genu-muscimol rats were not significantly different from those in the genu-saline group (Fig. $3 A$ ).

Voluntary movements were accompanied by a $7-8 \mathrm{~Hz}$ theta rhythm in a normal rat, which slowed to $4-6 \mathrm{~Hz}$ during ataxic walking after a general anesthetic (Fig. 4A,C). Gamma activity $(30-50 \mathrm{~Hz})$ in the hippocampal EEG (Bragin et al., 1995; Leung, 1998) was increased during the behavioral hyperactivity induced by halothane, compared with walking before halothane (Fig. 4A). After voluntary movements ceased, theta activity disappeared and gamma activity decreased (Fig. $4 A$ ). No increase in gamma activity was induced by halothane if muscimol was injected in the medial septum, but an additional decrease in gamma activity accompanied deep anesthesia after halothane (Fig. 4B). Similar results were obtained for isoflurane (data not shown). Hippocampal gamma activity was also increased during the phase of behavioral hyperactivity observed after administration of propofol (Fig. 4C) or pentobarbital (Leung, 1985). If the medial septum was inactivated, no increase in hippocampal gamma activity or behavioral activity was induced by $5 \mathrm{mg} / \mathrm{kg}$ intravenous propofol (Fig. 4D). Instead, rats appeared to be in deep anesthesia and showed reduced gamma activity compared with baseline walking (Fig. 4D). In conclusion, the behavioral excitation and depression induced by a general anesthetic were correlated with an increase and decrease in hippocampal gamma activity, respectively.

\section{DISCUSSION}

This study provides direct evidence that the hippocampus or the medial septum is necessary for the behavioral hyperactivity or 
Figure 3. Injection of muscimol into the medial septum, but not $2 \mathrm{~mm}$ above the septum, reduced behavioral excitation and enhanced the general anesthesia induced by pentobarbital. $A$, Interruptions of horizontal infrared beams were measured every minute after administration of $20 \mathrm{mg} / \mathrm{kg}$ intraperitoneal sodium pentobarbital, for four conditions: (1) $\square$, saline $(0.4 \mu \mathrm{l})$ injected into the medial septum (Septum-Sal); (2) $\mathbf{\square}$, muscimol $(0.4 \mu \mathrm{g}$ in $0.4 \mu \mathrm{l}$ of saline) injected into the medial septum (Septum-Mus); (3) $\bigcirc$, saline $(0.4 \mu \mathrm{l})$ injected $2 \mathrm{~mm}$ above the septum, in the genu of the corpus collosum (Genu-Sal); and (4) $\bullet$, muscimol $(0.4 \mu \mathrm{g}$ in $0.4 \mu \mathrm{l}$ of saline) injected in the genu (GenuMus). The same six rats were tested with saline or muscimol in a randomized manner, first with septal injections and then with genu injections. The Septum-Sal, Genu-Sal, and Genu-Mus groups all show an initially high amount of movements that declined with time, and none of these rats lost pain or righting responses. ${ }^{*} p<0.05 ;{ }^{\#} p<0.01$; difference between Septum-Mus and Septum-Sal groups; post hoc $t$ tests after repeated-measures ANOVAs. $B$, Duration of lost response to tail pinch (alligator clip) and righting reflex was measured 5 min after pentobarbital injection; means and SEMs ( $n=6)$ were
zero in all groups except for the Septum-Mus group. ${ }^{*} p<0.05$; difference between the Septum-Mus and Septum-Sal groups according to the paired Wilcoxon test.
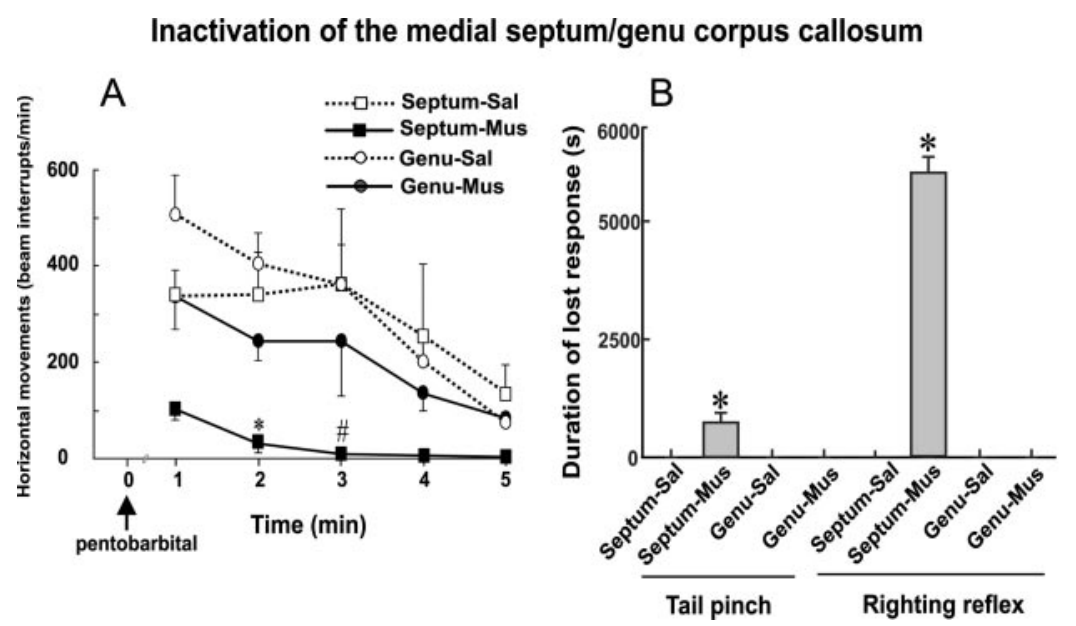

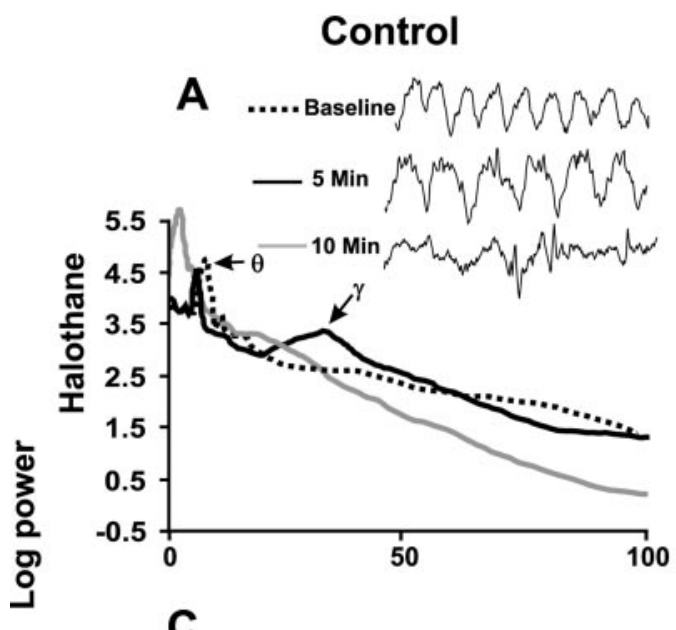

\section{Inactivated medial septum}
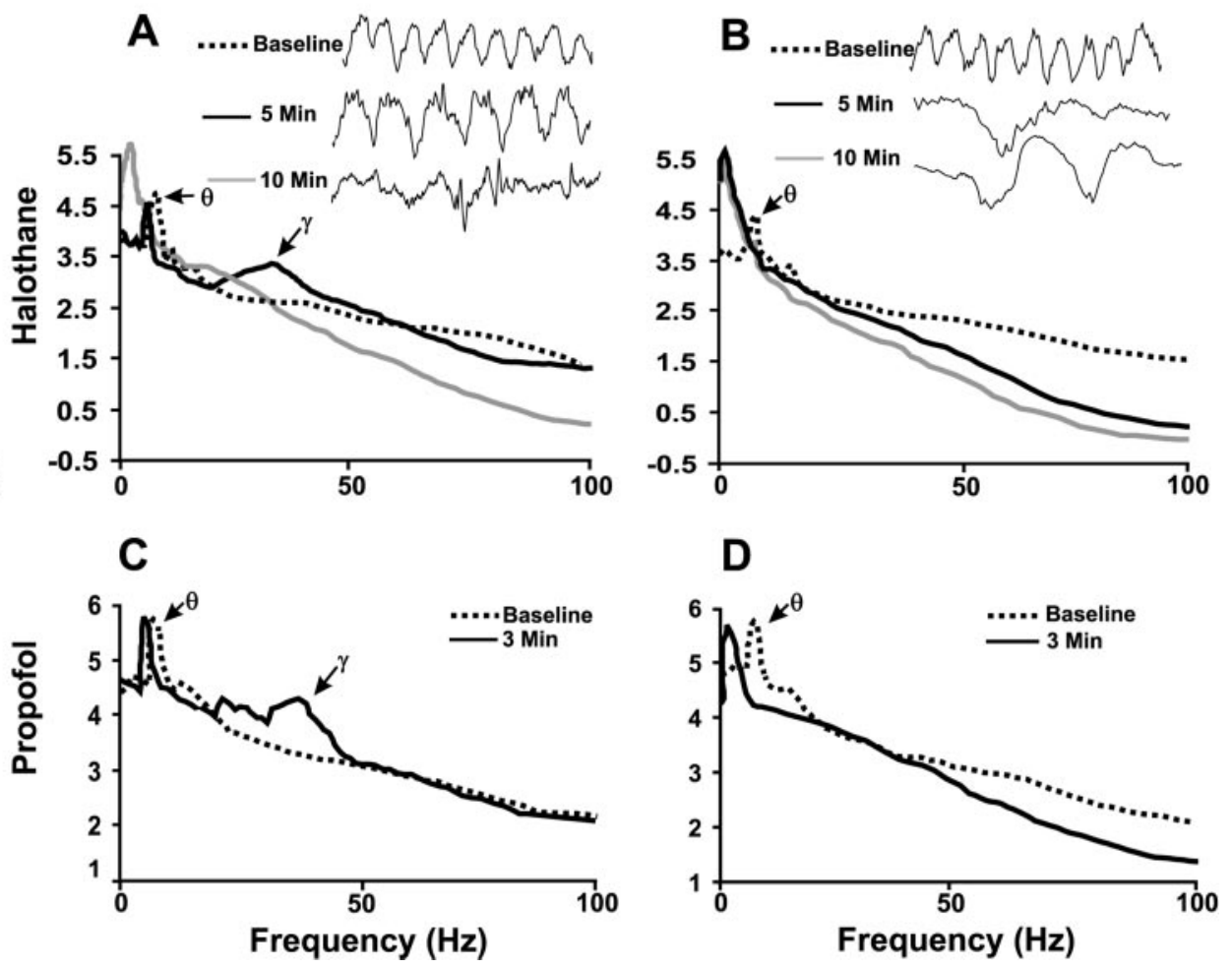

Figure 4. Hippocampal gamma waves increased with behavioral excitation in control rats and decreased with deep anesthesia in control and septuminactivated rats. $A$, Top, Raw EEG traces recorded in the CA1 stratum radiatum of a representative rat during three time periods: baseline walking (before any injection), $5 \mathrm{~min}$ after halothane (behavioral excitation phase), and $10 \mathrm{~min}$ after halothane (deep anesthesia). Bottom, Power spectra of the hippocampal EEG in the control rat, showing the slowing of theta activity and the increase in gamma activity at 5 min (anesthesia-induced behavioral excitation) and the abolition of both theta and gamma activity at $10 \mathrm{~min}$ (deep anesthesia). $B$, EEGs and power spectra before and after halothane in the same rat after muscimol injection in the medial septum. Theta activity was abolished in muscimol-injected rats, and halothane induced slow $(<1 \mathrm{~Hz})$ waves but no increase in gamma or behavioral activity. $C$, Power spectra of the hippocampal EEG in a control rat before and $3 \mathrm{~min}$ (behavioral excitatory phase) after $5 \mathrm{mg} / \mathrm{kg}$ intravenous propofol. Deep anesthesia was not induced in the control rat. $D$, Power spectra before and 3 min after propofol in a rat that had muscimol injected into the medial septum. Deep anesthesia was induced at $3 \mathrm{~min}$, and no gamma increase or behavioral hyperactivity was found at any time after propofol. Calibration of power spectrum: $6.3 \log$ units $=1 \mathrm{mV}$ peak-to-peak sine wave.

delirium induced by a general anesthetic. Stage II (delirium stage) of general anesthesia was accompanied by an increase in 30-50 $\mathrm{Hz}$ gamma waves in the hippocampus, whereas deeper anesthesia (stage III) was accompanied by diminished gamma activity. A hippocampal theta rhythm was present in stage II anesthesia and could still be induced by strong sensory stimulation during stage III anesthesia (Stumpf, 1965; Bland, 1986; Vanderwolf, 1988; Khanna and Zheng, 1999). Diminished 
gamma activity after a general anesthetic has been reported in other preparations (Whittington et al., 1996; Uchida et al., 2000). Medial septal inactivation or lesion is known to suppress theta waves and behavior (Bland et al., 1996; Oddie et al., 1996) and gamma waves (Leung, 1987; Ma and Leung, 1999, 2000).

Medial septal lesion is known to affect various behaviors of a rat, including increased reactivity to handling and loss of response inhibition (Grossman, 1978; O’Keefe and Nadel, 1978). Exaggerated response to handling was more apparent after a high $(1 \mu \mathrm{g})$ than a low $(<0.5 \mu \mathrm{g})$ dose of muscimol administered to the medial septum, and this response was not apparent after muscimol injections into the hippocampus. All movements induced by a general anesthetic were strongly attenuated in rats with septohippocampal inactivation compared with control rats. However, septohippocampal inactivation by itself did not induce any sign of anesthesia, and after inactivation, a rat was responsive to touch, sound, and light, and was capable of righting itself. Latency of paw withdrawal on a hot plate was not different between septumor hippocampus-inactivated rats and controls (data not shown), suggesting that the pain threshold was not critically altered by septohippocampal inactivation.

Our most important finding is that inactivation of the septohippocampal system increases the potency of a general anesthetic. Control rats required $\sim 10 \mathrm{mg} / \mathrm{kg}$ intravenous propofol and $>45$ $\mathrm{mg} / \mathrm{kg}$ intraperitoneal pentobarbital to abolish the tail-pinch response, compared with $5 \mathrm{mg} / \mathrm{kg}$ intravenous propofol and 20 $\mathrm{mg} / \mathrm{kg}$ intraperitoneal pentobarbital in hippocampal- or septalinactivated rats. Thus, the potency of propofol or pentobarbital was enhanced by $\geq 100 \%$ after septohippocampal inactivation. Septohippocampal inactivation also enhanced the potency of halothane or isoflurane, because normally subanesthetic doses of halothane or isoflurane induced deep anesthesia with concomitant septohippocampal inactivation. How inactivation of the septohippocampal system potentiates general anesthesia is not known. Mediation through the thalamocortical system, normally regarded as important for arousal, is not ruled out, but more immediate neural pathways are as follows: First, the hippocampus mediates movements in part by a direct projection to the nucleus accumbens, which in turn projects to the ventral pallidum, midbrain locomotor areas, hypothalamus, and frontal cortex (Vanderwolf, 1988; Mogenson et al., 1993; Skinner and GarciaRill, 1993; Pennartz et al., 1994; Ma et al., 1996). Second, the septohippocampal system is normally activated by pain (Khanna and Zheng, 1999), and the nucleus accumbens has been shown to be involved in forebrain-mediated suppression of pain (Ma and Han, 1991; Gear et al., 1999). Third, connections of the medial septum with the mesopontine cholinergic neurons (Semba and Fibiger, 1992) may help to maintain overall vigilance and influence the sleep-wake states (Steriade et al., 1991; Jones, 1993). A decrease in the central acetylcholine level has been shown to increase general anesthetic potency (Zucker, 1991), and cholinergic stimulation can induce EEG and behavioral arousal (Vanderwolf, 1988; Meuret et al., 2000). Through the above pathways, a general anesthetic may initially induce movements and subsequently suppress pain, awareness (consciousness), and movement control. Complete inactivation of the septohippocampal outputs may facilitate all of the desirable clinical effects of a general anesthetic, including the loss of consciousness, pain, voluntary movements, and memory (Squire, 1992).

To our knowledge, this is the first study that reports a septohippocampal influence on the effects of general anesthesia. The results are not at odds with previous reports indicating that general anesthetics suppress pain-induced behaviors at the spinal level. The findings that spinal cord transection and precollicular decerebration did not alter the anesthetic potency in acute preparations (Rampil et al., 1993; Rampil, 1994) do not exclude the possible selective facilitatory and inhibitory effects that the brain may exert on the spinal cord in a behaving animal. Specific nociceptive and anti-nociceptive pathways are known in the spinal cord (Fields and Basbaum, 1994). An increase in anesthetic (halothane) requirement when only the brain was preferentially perfused with anesthetic-loaded blood (Antognini and Schwartz, 1993) may suggest that halothane did not inactivate the septohippocampal system effectively. Although general anesthetics depressed hippocampal neural activity (Kendig et al., 1991; Krnjevic, 1991; Tanelian et al., 1993; Tanner et al., 2000), it appears that muscimol suppresses local neural activity more completely than any general anesthetic used alone. Thus, we suggest that more potent general anesthetics or adjuvants may be developed to maximize the pharmacological depression of the septohippocampal system.

\section{REFERENCES}

Antognini JF, Schwartz K (1993) Exaggerated anesthetic requirements in the preferentially anesthetized brain. Anesthesiology 79:1244-1249.

Bland BH (1986) The physiology and pharmacology of hippocampal formation theta rhythms. Prog Neurobiol 26:1-54.

Bland BH, Trepel C, Oddie SD, Kirk IJ (1996) Intraseptal microinfusion of muscimol: effects on hippocampal formation theta field activity and phasic theta-on cell discharges. Exp Neurol 138:286-297.

Bragin A, Jando G, Nadasdy Z, Hetke J, Buzsaki G (1995) $\gamma(40-100$ $\mathrm{Hz}$ ) oscillation in the hippocampus of the behaving rat. J Neurosci 15:47-60.

Clark DL, Rosner BS (1973) Neurophysiologic effects of general anesthetics: the electroencephalogram and sensory evoked responses in man. Anesthesiology 38:564-582.

Fields HL, Basbaum AI (1994) Central nervous system mechanisms of pain modulation. In: Textbook of pain (Wall PD, Melzack R, eds), pp 243-257. Edinburgh: Churchill Livingstone.

Franks NP, Lieb WR (1994) Molecular and cellular mechanisms of general anaesthesia. Nature 367:607-614.

Freund TF, Buzsaki G (1996) Interneurons of the hippocampus. Hippocampus 6:347-470.

Gear RW, Aley KO, Levine JD (1999) Pain-induced analgesia mediated by mesolimbic reward circuits. J Neurosci 19:7175-7181.

Grossman SP (1978) An experimental "dissection" of the septal syndrome. In: Functions of the septohippocampal system. Ciba Found Symp 58:227-274.

Guedel AE (1951) Inhalation anesthesia: a fundamental guide, Ed 2. New York: Macmillan.

Jones BE (1993) The organization of central cholinergic systems and their functional importance in sleep-waking states. Prog Brain Res 98:61-71.

Kendig JJ, MacIver B, Roth SH (1991) Anesthetic actions in hippocampal formation. Ann NY Acad Sci 625:37-53.

Khanna S, Zheng F (1999) Morphine reversed formalin-induced CA1 pyramidal cell suppression via an effect on septohippocampal neural processing. Neuroscience 89:61-71.

Krnjevic K (1991) Cellular mechanisms of anesthesia, actions of alcohol, and anesthetics at the cellular level. Ann NY Acad Sci 625:1-16.

Leung LS (1985) Spectral analysis of hippocampal EEG in the freely moving rat: effects of centrally active drugs and relations to evoked potentials. Electroencephalogr Clin Neurophysiol 60:65-77.

Leung LS (1987) Hippocampal electrical activity following local tetanization. I. Afterdischarges. Brain Res 419:173-187.

Leung LS (1998) Generation of theta and gamma rhythms in the hippocampus. Neurosci Biobehav Rev 22:275-290.

Ma J, Leung LS (1999) Medial septum mediates the increase in postictal behaviors and hippocampal gamma waves after an electrically induced seizure. Brain Res 833:51-57.

Ma J, Leung LS (2000) Relation between hippocampal gamma waves and behavioral disturbances induced by phencyclidine and methamphetamine. Behav Brain Res 111:1-11.

Ma J, Brudzynski SM, Leung LS (1996) Involvement of the nucleus accumbens-ventral pallidal pathway in postictal behavior induced by a hippocampal afterdischarge in rats. Brain Res 739:26-35.

Ma QP, Han JS (1991) Neurochemical studies on the mesolimbic circuitry of antinociception. Brain Res 566:95-102.

Meuret P, Backman SB, Bonhomme V, Plourde G, Fiset P (2000) Phy- 
sostigmine reverses propofol-induced unconsciousness and attenuation of the auditory steady state response and bispectral index in human volunteers. Anesthesiology 93:708-717.

Mogenson GJ, Brudzynski SM, Wu M, Yang CR, Yim CY (1993) From motivation to action: a review of limbic-nucleus accumbens-ventral pallidum-pedunculopontine nucleus circuitries involved in limbicmotor integration. In: Limbic motor circuits and neuropsychiatry (Kalivas P, Barnes CD, eds), pp 193-236. Boca Raton, FL: CRC.

Moruzzi G, Magoun HW (1949) Brain stem reticular formation and activation of the EEG. Electroencephalogr Clin Neurophysiol 49:455-473.

Oddie SD, Stefanek W, Kirk IJ, Bland BH (1996) Intraseptal procaine abolishes hypothalamic stimulation-induced wheel-running and hippocampal theta field activity in rats. J Neurosci 16:1948-1956.

O'Keefe J, Nadel L (1978) The hippocampus as a cognitive map. New York: Oxford UP.

Paxinos G, Watson C (1986) The rat brain in stereotaxic coordinates. Sydney: Academic.

Pennartz CM, Groenewegen HJ, Lopes da Silva FH (1994) The nucleus accumbens as a complex of functionally distinct neuronal ensembles: an integration of behavioural, electrophysiological, and anatomical data. Prog Neurobiol 42:719-761.

Rampil IJ (1994) Anesthetic potency is not altered after hypothermic spinal cord transection in rats. Anesthesiology 80:606-610.

Rampil IJ, Mason P, Singh H (1993) Anesthetic potency (MAC) is independent of forebrain structures in the rat. Anesthesiology 78:707-712.

Semba K, Fibiger HC (1992) Afferent connections of the laterodorsal and the pedunculopontine tegmental nuclei in the rat. J Comp Neurol 323:387-410.

Skinner RD, Garcia-Rill E (1993) Mesolimbic integrations with me- sopontine modulation of locomotion. In: Limbic motor circuits and neuropsychiatry (Kalivas P, Barnes CD, eds), pp 155-182. Boca Raton, FL: CRC.

Squire LR (1992) Memory and the hippocampus: a synthesis from findings with rats, monkeys, and humans. Psychol Rev 99:195-231.

Steriade M, Curro Dossi R, Pare D, Oakson G (1991) Fast oscillations $(20-40 \mathrm{~Hz})$ in thalamocortical systems and their potentiation by mesopontine cholinergic nuclei in the cat. Proc Natl Acad Sci USA 88:4396-4400.

Stockard J, Bickford R (1975) A basis and practice of neuroanaesthesia (Gordon E, ed), pp 3-46. Amsterdam: Excerpta Medica.

Stumpf C (1965) Drug action on the electrical activity of the hippocampus. Int Rev Neurobiol 8:77-138.

Tanelian DL, Kosek P, Mody I, MacIver MB (1993) The role of the $\mathrm{GABA}_{\mathrm{A}}$ receptor/chloride channel complex in anesthesia. Anesthesiology 78:757-776.

Tanner KM, Obasi C, Herrick IA, Leung LS (2000) The effects of propofol on hippocampal synaptic transmission in behaving rats. Anesthesiology 93:463-472.

Uchida S, Nakayama H, Maehara T, Hirai N, Arakaki H, Nakamura M, Nakabayashi T, Shimizu H (2000) Suppression of gamma activity in the human medial temporal lobe by sevoflurane anesthesia. NeuroReport 11:39-42.

Vanderwolf CH (1988) Cerebral activity and behavior: control by central cholinergic and serotenergic systems. Int Rev Neurobiol 30:225-340.

Whittington MA, Jefferys JG, Traub RD (1996) Effects of intravenous anaesthetic agents on fast inhibitory oscillations in the rat hippocampus in vitro. Br J Pharmacol 118:1977-1986.

Zucker J (1991) Central cholinergic depression reduces MAC for isoflurane in rats. Anesth Analg 72:790-795. 